\title{
Nachman Krochmal and the Argument from Design
}

\author{
Robert Elliott Allinson \\ (Soka University of America, USA) \\ e-mail: rallinson@soka.edu
}

Key words: Argument from Design, Spinoza, Deism, Kant, internal final causes, Darwinian evolution, Aristotle, Bertrand Russell, the Hebrew Bible, Krochmal, ontological argument, causal ontological argument

\begin{abstract}
For the nineteenth century Jewish Galician philosopher, Nachman Krochmal (17851840), the argument from design is the most powerful argument in Jewish literature. This paper is separated into seven parts, each of which aims to give the reader a better understanding of the argument from design. In each part, the argument is compared and contrasted with other arguments for and against the existence of G-d from classical Western philosophers up until current writers. Historical and contemporary objections to the argument from design are shown to be based upon philosophical misunderstandings. The thesis of this article is that the argument from design remains the most powerful argument for the existence of G-d. In addition, in contrast to other arguments for the existence of G-d, such as the ontological arguments, it is the metaphysical argument that is closest to the nature of the G-d of worship of the Jewish religion.
\end{abstract}

In his well thought out book on the Jewish Galician philosopher Nachmal Krochmal, Jay Harris points out that Krochmal held that the argument from design is, "... according to Krochmal, a cardinal principle of Jewish faith" and that "of all the arguments in favor of the existence of G-d, the fact that the ordered world would be inconceivable without him may be the most powerful in Jewish literature". ${ }^{1}$ Given the atheistic world view that dominates today's intellectual climate, in which the argument from design is lightly tossed aside, it behooves us to closely examine the argument from design.

I would like to divide this article into seven parts. Firstly, we shall contrast the argument from design with its most powerful theistic opposite, the great philosophy of Spinoza. Secondly, we shall examine Krochmal's replies to Kant's objections to the argument from design. Thirdly, we shall contrast the argument from design with its most powerful atheistic opposite, the argument that chance, not design, serves as the most likely explanation of the universe. Fourthly, we shall examine the classic atheistic objections to the argument from design put forth by Bertrand Russell. Fifthly, we shall examine the recent objections to the argument from design put forth by Rebecca Goldstein. Sixthly, we shall examine the relationship between Goldstein and Spinoza. Seventhly, we shall examine the ethical argument for the existence of a designer, the argument from care.

\footnotetext{
1 Harris 1993.
} 


\section{Krochmal and Spinoza}

Krochmal cites Spinoza's objection to the notion that G-d serves any teleological purpose, such as a caretaker of the universe, because, according to Spinoza, G-d would then be subservient to that end. ${ }^{2}$ This argument that Krochmal attributes to Spinoza reminds one of Aristotle's argument that the Unmoved Mover could not think of the universe, despite Averroes ingenious objection, because that would be to think of an inferior object and would then mar G-d's perfection. In the Appendix to Book I of his Ethics, Spinoza's posthumously published magnum opus, Spinoza writes:

All the prejudices I here undertake to expose depend on this one: that men commonly suppose that all natural things act, as men do, on account of an end; indeed, they maintain as certain that G-d himself directs all things to some certain end, for they say that G-d has made all things for man, and man that he might worship G-d. ${ }^{3}$

I answer that, although G-d may have an end in mind, it does not follow that G-d exists for the sake of that end. Hence, teleology does not necessarily detract from G-d's perfection. Further, while G-d may be the Divine Architect, it does not follow that $\mathrm{S} / \mathrm{He}$ designs the universe for any exterior purpose. The argument from design does not depend upon any purpose outside of itself. To echo the aesthetic theory of Walter Pater, the creation of the universe could be a creation for its own sake. This may not answer Aristotle's argument that such an action may detract from G-d's perfection. This, however, depends upon how one defines perfection. One could argue that care for others is a mode of perfection which is more perfect than thinking about thinking, the activity that preoccupied Aristotle's Unmoved Mover.

Krochmal's argument from design proceeds in two ways. The first way is an argument from ethics. He cites the Hebrew Bible for evidence that G-d would not create the world and then not act as caretaker of it. ${ }^{4}$ This is not the usual argument from design which argues from the elaborate and comprehensive order of things to the existence of a designer. Let us, for the moment, concentrate on the more traditional nature of the argument from design. At the end of this essay, we shall return to the caretaker argument.

Krochmal does not simply argue from the existence of the extraordinary order of the universe and the harmony of the co-existence of all of its parts. His argument from design is what can be referred to as the teleological relationship between the parts of an organism and its end. This is my terminology and not Krochmal's, but I think that it helps to clarify his arguments and illustrate their distinctive nature. In his words, "The teleological principle ... is internal, because the various parts of the body are not explicable, either in terms of their existence or their function, without the notion of the structure as a whole serving as the telos for which these parts came into existence." ${ }^{5}$ An easy example

\footnotetext{
${ }^{2}$ Harris 1993: 47-48.

${ }^{3}$ Spinoza 1985.

${ }^{4}$ I do not examine the relationship of Krochmal's thinking to the Jewish philosopher Abraham Ibn Ezra (1089-1164) or to Hegel (1770-1831) because it would take us too far afield from the main argument of this

${ }^{5}$ Harris 1993: 51.
} present article. 
(not one that Krochmal provides) is the existence of a hand which would make no sense except as part of an organism that it serves as a feeder, protector, and so on and so forth.

Krochmal reasons from the existence of internal teleology that "... a thinking, willing G-d must be responsible for the creation of complex organisms." Otherwise, (and this reasoning is my own), how or why should such complex organisms come into being? The only other option is chance, an option which will be examined in detail in Part III. Such options as genes or memes who are choosing to construct host organisms for their own survival are both too fantastic to consider, and also suffer from the same problem, to wit, why or how do these genes succeed in creating internally teleological organisms? Is it also from chance or do they become the designers of the universe? In the latter case, this is still a variation of the argument from design - although it is one which does not contain much ethical or spiritual value.

Even Spinoza, in his thirty-second letter to Oldenberg, appears to present arguments that support the argument from design (he does not use the word 'design' but rather refers to an agreement of the part with the whole and with all other parts) though he professes to be ignorant on how or why such a harmony exists in the first place:

When you ask me my opinion on the questions raised concerning our knowledge of the means, whereby each part of nature agrees with its whole, and the manner in which it is associated with the remaining parts, ... as to the means whereby the parts are really associated, and each part agrees with its whole ... I am in ignorance. ${ }^{7}$

It seems that Spinoza does consider that there is an agreement that exists among the parts of nature, though he does not attribute this to a design. Most importantly, as to how this agreement comes about, he professes ignorance and thus relieves himself from the need to argue for or against the presence of design. The problem with this approach is that it leaves the question of the order of nature unexplained. Spinoza, however, has an astute answer to this question: “... I will premise that I do not attribute to nature either beauty or deformity, order or confusion. Only in relation to our imagination can things be called beautiful or deformed, ordered or confused." 8 On the one hand, Spinoza appears to recognize a harmony of parts with a whole that exists in nature; on the other, he premises that this is simply the result of our imagination. Spinoza does not explain why we are prone to see order in the universe. Is this a universal hallucination? Later in the same letter, Spinoza states: “... each body ... must be considered as a part of the whole universe, as agreeing with the whole, and associated with the remaining parts."

If this is an instance of our imagination ordering the universe, then the question is, why does he say that our imagination must work in this fashion? Is this a prelude to Kant's later argument found in the Transcendental Deduction of the Categories in his first Critique?

There is but a short step from Spinoza's concept of the imagination imposing order on the universe to Kant's reduction of order to a means by which our judgment reflects upon the universe and so it is to Krochmal's treatment of Kant that our attention must

\footnotetext{
6 Ibid.: 51.

7 Spinoza 1891: 290.

8 Ibid.: 290.

9 Ibid.: 292.
} 
now turn. Kant also does not explain why we must order the universe in the way that we do. He presents complex arguments to demonstrate that we must think the way we do in order to possess coherent experience, but he never presents any arguments to demonstrate why we must possess coherent experience.

Spinoza, on the other hand, does not shy from metaphysical arguments. However, we may well wonder why Spinoza continues to do metaphysics in light of his declaration that our concepts about the universe are only our imaginations and do not describe reality itself. We may also wonder whether Spinoza's restriction of conceptualizations of the universe to the work of the imagination does not constitute an anticipation of Kant's famed restriction of knowledge to appearances and a denial that our knowledge can penetrate to things as they exist in themselves. It seems that it also prefigures Darwin's and later Dawkins's arguments that there is an illusion of design, but why the appearance of a design is an illusion is a question to which we shall return later. Why there is even an illusion of design is a question that needs to be addressed.

\section{Krochmal and Kant}

Kant does not object to the idea of internal final causes and a system of purposes, but he does not see how this justifies the inference from internal causality to G-d. We may refer to Kant's position as a half-way house. If we start with Kant's position, the case for the argument from design possesses a stronger foundation than the position of starting with a universe of elements that are grouped together purely by chance (which is an incoherent notion as we shall see below). If we already possess a system of internal teleological causes, we can ask the question, how or why do these internal, teleological causes interact with each other? From the argument of ecological balance, it appears that internal, teleological causes relate to each other in both internal and external dependencies.

The next set of questions is how or why does this elaborate system of internal and external dependencies come into being and continue without governance or supervision? That this degree of a complexity of unity and order is due to natural selection does not answer the question as to why there is natural selection in the first place. Even the hypothesis of natural selection that operates with such amazing regularity and co-operative harmony makes more sense if one assumes a regulator and supervisor than if such regularity and co-operative harmony is assumed to come into being and maintain itself by chance. Again, the argument from chance will be examined in Part III. For the present, it may be said that while Kant may assert that we cannot justify the move from internal causality to G-d, if we do not make such a move, we are left with a system without any basis or ground of its systematic nature. We have a system that possesses no reason for its being there as a system. The justification that Kant asserts to be lacking is the very existence of a systematic relationship among internal, teleological organisms. The incoherency of the position that such a system exists and continues to exist without an organizer is the very basis for the argument for design.

Kant is satisfied that he has established the possibility of internal final causes and this enables him to conclude that nature consists of an overall system of final causes. One of Kant's examples is that of a tree, which produces leaves, which in turn maintain it, 
"for repeated defoliation would kill it..."10 However, Kant does not think that the system of internal final causes proves the existence of a designer. For Kant, all that the existence of a system of internal cause proves is that nature is made up of a system of internal causes. (There are external causes as well, but the existence of external causes does not affect the argument). For the present author, the question then becomes, how does a system of internal causes design itself?

The importance of stressing the existence of internal causes is that it is very difficult if not impossible to utilize the explanation of natural selection to account for internal teleology. We can offer a humorous example to illustrate this point. In contrast to the argument that giraffes grew long necks in order to reach the leaves on the tops of tall trees, Darwinian evolution would argue that it was natural selection that enabled long necked giraffes to survive because they could reach the tops of trees. The question remains, why does a giraffe exist at all in the first place? Natural selection cannot account for the first giraffe. One could argue that a giraffe is a result of the evolution of genes that formed this particular survival entity in all of its elegant, colorful, improbable and delightfully comic form. This kind of argument is similar to the argument that given sufficient time, a number of chimpanzees hammering on the keys of computers given to them would eventually write the works of Shakespeare. Kant appears to argue that internal causes are produced by the parts of the organisms themselves:

Its parts must in their collective unity reciprocally produce one another alike as to form and combination, and thus by their own causality produce a whole ... In such a natural product as this every part is thought as owing its presence to the agency of all the remaining parts and also as existing for the sake of the others and the whole ... ${ }^{11}$

If every part owes its existence to all of the other parts, how can any part exist by itself in the first place? Indeed, it is difficult if not impossible to comprehend that it is via the causality of the parts that the whole comes into being.

From Kant's reasoning, one would infer that nature, as a whole, would come into being from the collective unity of its parts. Kant, however, does not conclude this. It must be remembered that Kant does affirm a system of purposes and that, according to the above reasoning, each organism is either responsible for its separate existence or the entire system of nature is brought about by the collective unity of its parts. If in the above quotation, Kant intends to restrict the meaning of the word "part" to a singular part of a single organism (the leaf of a tree, for example), then the collective unity of all the parts of nature must be the result of chance. One could argue natural selection for each part, but this does not account for the existence of natural selection in the first place. If, on the other hand, by the word "part", Kant intends that all the parts of nature collectively bring about the whole, then this would imply a metaphysics of a teleological design on the part of parts which would appear to be at least as fantastic as the concept of an intelligent designer of the whole. Kant avoids these consequences by stating that:

\footnotetext{
10 Kant 2007: 374.

11 Ibid., \#65 (emphasis in original).
} 
... no one would ascribe design to a lifeless material ... we do not convert nature into an intelligent being, for that would be absurd, but neither do we think of placing another being, one that is intelligent, above nature as its architect, for that would be presumptuous. ${ }^{12}$

For Kant, the concept of teleology is only meant to serve as a reflective concept and is not to be taken to possess an ontological status, that is, in his words, a constitutive principle of nature. Kant makes it clear that his concept of teleology cannot be construed as an argument for the existence of G-d. It is meant to apply to how we judge nature, nothing more. How and why it can possess an epistemological application without ontological status is left as a puzzle for readers of Kant. For Krochmal, one can take Kant one step further: the existence of a system of internal purposes is best explained by a designer, G-d.

The argument from the existence of a system of internal purposes is stronger than the argument from an assembly or aggregation of mechanisms. Once one has established that there are internal purposes in nature, it is less likely to be preposterous that there is a purposeful designer.

Kant's arguments that nature is a system of purposes creates the opportunity for Krochmal's argument from design. One may say that Judaism can benefit from the arguments of Kant in the same fashion as both Judaism and Christianity benefited from the arguments of Aristotle, but only more so. In the case of Aquinas and Maimonides utilizing Aristotelian arguments for the existence of the Deity, (in Maimonides' words), they were successful in proving that G-d is, not what G-d is. For Aristotle, as said above, G-d had no interest in this world and hence his proofs do not lead to a G-d with whom one can worship, petition and co-create.

Kant opens the door to a purposeful G-d. Although, of course, he denies that this is an idea that possesses reality and is only a regulative idea, his arguments from a nature composed of final ends provides a logical base for a purposeful G-d. This is why, in my opinion, Krochmal focuses on Kant's arguments for a teleological view of nature.

My argument is as follows: If nature is made up of mechanical causes, it is entirely possible that Deism, an $18^{\text {th }}$ century version of Aristotelianism, is correct. As Jefferson thought, G-d is only necessary as a starter of the cosmos. He then can leave the scene, making it entirely unnecessary for Him to die, as Nietzsche (or Zarathustra) proclaimed.

If, on the other hand, nature is made up of a kingdom of ends - to borrow a Kantian phrase - then the bridge to a purposeful G-d has been provided. For, if the parts of nature (excluding external causes) are teleologically driven, then why should the whole of nature be made of a different cloth ${ }^{13}$ If each part of nature, for example a tree, is a purposeful organism, then why should all the parts of nature together lack a purpose? One accounts for each organism as a purposeful entity, making it unlikely that that entity lacks a design. Each entity, thus, is an illustration and an embodiment of a designed entity. A design cannot be the result of any one part or the summation of all parts because the whole, that is the end goal, must pre-exist in order for the part to exist in the first place. An arm, for example, cannot pre-exist for a body. The body, as an end goal, must pre-exist as a design in order to make it necessary to create an arm to feed and protect it.

12 Ibid., \#68, 383.

${ }^{13}$ Harris writes that "Having established the possibility of internal final causes, Kant feels justified in affirming a 'system of purposes' ... in which we do not need to be able to prove an internal causality for each part of the system to be able to nevertheless affirm the final causality that inheres within it." Harris 1993: 49. 
The body does not exist for the sake of the arm. The arm exists for the sake of the body. The idea of the body must precede the idea of the arm.

Nature is a unity since all of its parts work together under a cooperative principle which we call ecology. The whole exists as a sustaining principle for every part. If the whole exists as a unity, then the idea of the whole must pre-exist the idea of the parts. If each of the parts possesses a design, and the parts together function as a whole, then the whole itself must also possess a design.

The value of incorporating Kantian teleology is that if the whole itself has a design, then this illustrates that the whole itself requires a designer. The argument for a Deity then turns on the concept of the designer. As we shall discuss below, if a designer fashions a design, then the designer possesses a responsibility for caring for that design. The introduction of the idea of purposes in nature leads the way to a purposeful G-d who then, unlike the G-d of Aristotle, can be implored to care for His design. In this sense, Kant's epistemology can be utilized as a metaphysics, which allows for the G-d of religion. This is Krochmal's contribution.

For Kant, to turn a regulative principle - our way of judging nature - into a constitutive principle - a teleology into a theology — is presumptuous (his word). For Kant, the belief in G-d is to be left untarnished by rational proof, to the realm of Faith. It is not clear that we need this bifurcation into the realms of Faith and Reason for this creates an unnecessary division that provides grounds for conflict and disharmony. Faith and Reason can be partners on a journey, each contributing something distinctive to the creation of a theology without denigrating one or the other.

\section{The idea of chance}

For Dawkins, the idea of chance is all that is needed for the existence of the universe in the first place. After the chance event that precipitated the universe, Darwinian evolution, based upon natural selection, is sufficient to explain the subsequent development. The idea of chance is not needed. It is only required for the explanation of the beginning.

We have disposed of the idea that evolution can account for the ecological harmony of the parts of the universe and the synchronicity of the whole that enables the parts to function. Evolution can suffice to explain the survival of certain species. That is about all.

Now it is time to dispose of Dawkins's parallel notion, that chance can explain the origin of the universe. Such a notion is a confusion of epistemological and ontological orders.

The universe cannot come into being as a result of chance. Chance is not a cause because chance is an epistemological concept, not an ontological concept. Chance is not an explanation. Chance is the absence of an explanation. The idea of chance or the representation of the concept of chance under the guise of statistical probability is an epistemological not an ontological concept. A regular pattern must first exist before one can compare it to an irregular pattern or the lack of a pattern. Chance is not a primary concept. Chance is a parasitic concept, parasitic upon ontological occurrence. To say that the universe comes to be or exists by chance is not an argument, but only reveals a lack of understanding the meaning of the concept of chance. 
The idea of chance in and of itself is not a primary or an explanatory concept. The concept of a "singular beginning chance event" is a verbal phrase made of a string of four successive words that possess no coherent meaning. Chance is not a cause; it is a concept. It is a concept that stands for the fact that one does not know the cause of an event. In our contemporary usage of the concept of chance, chance is a concept that both reveals and conceals our ignorance.

For Aristotle, chance occurrences are defined by the intersection of two caused events. Chance by itself does not determine anything. It is a reflection, for Aristotle, of how two self-determining events can possess an unintended consequence. What is a singular self-caused event for Aristotle is what he calls the spontaneous. The spontaneous, for Aristotle, is a wider category than chance. What happens of itself is not caused by chance or randomness, because chance or randomness are not causes; they are derivative epistemological concepts.

\section{Krochmal and Bertrand Russell}

In his influential work Why I am not a Christian?, Bertrand Russell raises the apparently obvious key counter-argument to all arguments for the existence of G-d. This argument, simply put, is that if one argues that the existence of the world makes no sense without appeal to a creator, the problem is not solved by saying that it was created by G-d. The reason this apparent solution is untenable, according to Lord Russell, is that it only pushes the question one step further back to, who created G-d? Since this cannot be answered, or would lead us into an infinite regress, to argue that the existence of the universe is explained by referring to the existence of G-d, is no help at all. So ends the final coup de grace of Russell, with the argument to which any atheist worthy of the name 'atheist' appeals, "Who then created G-d?"

The question, "Who created G-d?" is a different question from the question, "Does the existence of a design require a designer?" These questions are not on the same level. One question possesses a clear and definite content; the other does not. The existence of a design makes us think that it is more plausible (not that it necessitates us) to consider that there is a designer than not. This is not a proof of the existence of a designer. It is an argument from plausibility. The most famous illustration of the argument is Paley's anecdote of finding a watch on the heath. We draw the inference from the existence of a watch that there is a watch maker. It is not a necessary inference. It is logically possible that the watch materialized itself. However, we do not consider that this is plausible. It is logically possible but empirically absurd. Hence, we think it is far more likely that there is a watch maker. The argument from design is not any different than this. It is an argument from likelihood, not logical necessity.

The argument from design is not faulted by the objection, "Who then made G-d?" any more than the argument from the existence of the watch to a watch maker is invalidated by the question, "Who made the watch maker?" This is a separate question and deserves a separate answer. The questions of "Who made G-d?" and "Who made the watch maker?" need separate treatments. If, for example, an archeologist finds potsherds on a dig, the archeologist may infer that there were humans living on that site at some 
point in the past. The question of who made these human beings is a separate question altogether and does not invalidate the first inference.

In addition, the question "Who made G-d?" assumes that G-d is an existence that needs to be created. If G-d is uncreated and eternal, then the question is wrong-headed. The world, we think, can be argued to have a beginning. This is because scientific evidence can be cited for the likelihood of the lifetime of carbon atoms, stars, etc. It is plausible for us to consider that the world had a beginning in time. We have the content of a subject matter to examine. In the case of G-d, we have no content of a subject matter to examine. We have no basis for considering that G-d had a beginning. We have two cases to examine and each one refers to a different subject matter. In one case, we have content to examine (that of the universe); in the other case, we have no content to examine (that of G-d). The two different questions cannot be conflated. They exist on different levels. It makes sense to ask, "Who created the universe?" It does not make sense to ask, "Who created G-d?" That both questions can be asked in grammatical English does not mean that both questions make sense. That the question of design can be provided with the plausible answer of a Divine Designer, is not negated by the fact that the question of who created G-d cannot be answered at all. The question of who created G-d is not a real question because there are no grounds for inferring that G-d is an existence that possesses a lifetime whereas all parts of the universe can be analyzed on scientific grounds as possessing a lifetime.

The scientist Richard Dawkins has argued against the argument from design that Darwin's theory of evolution and the survival of the fittest explains the way in which the world and all the creatures within it have evolved.

I answer that, though the survival of individual entities might be explained by the notion of the survival of the fittest, this notion cannot explain the overall order of the universe. The survival of individual entities does not require the extraordinary unity of the universe. Since the overall unity of the universe does exist, the overall unity of the universe does not come into being as a result of the survival of the fittest. Darwinian theory, then, might account for the continued existence of certain species, but it cannot and does not explain the existence of the harmony of ecological units that make up the totality.

\section{Krochmal and Rebecca Goldstein}

A recent writer, Rebecca Goldstein, has taken on the Argument from Design to show its inadequacies. It is the third of thirty-six arguments for the existence of G-d that she proposes to debunk in her book, Thirty-Six Arguments for the Existence of G-d. For the flaw that she sees in this argument she draws upon no less an authority than Charles Darwin who, according to her, had already shown that "... the process of replication could give rise to the illusion of design without the foresight of an actual designer. Replications make copies of themselves, which make copies of themselves ... After many generations, the dominant replicators will appear to have been designed for effective replication ..." ${ }^{\prime 14}$ This argument commits the fallacy of begging the question.

\footnotetext{
${ }^{14}$ Goldstein 2010: 351-352.
} 
The "answer", 'replication', is a question, not an answer; why is there replication in the first place? This question is no different from the question, why is there existence in the first place? Replication is simply an observation that existing entities tend to reproduce themselves. It entirely leaves behind the question, why. Replication, in effect, is another variation on the theme of chance. Replication does not draw upon the explanation of natural selection. Why do organisms replicate themselves? If it is in order to survive, does this mean that there is an instinct to survive on the cellular level? Why does this "instinct" exist in the first place? Natural selection could possibly explain why certain cells survive, but why is survival a phenomenon in the first place?

It could well be argued that replication is another word for reproduction and reproduction of a species is a means by which the species can survive. This, too, reflects design. The species must be designed to survive and replication is its means. One can, of course, always assert that the drive for survival is a product of chance, but, as we have seen above, and we shall see below, this is a misuse of the concept of chance.

To answer that there is an illusion of design is not an answer to why there is such an illusion. The question, "Is it plausible that such an exquisitely functioning universe can exist without a designer," now becomes this: "How can such an illusion of an exquisitely functioning universe exist without a designer?" Even copies of designer products, such as exquisite leather hand bags, have been known, upon personal inspection, to deceive their designers, such as Louis Vuitton, into thinking that they were products of the original manufacturers. But, the copies also had manufacturers. Indeed, the reason that Louis Vuitton could not tell them apart was that they were made in the same factory in China.

Goldstein also invokes what she calls the Fallacy of Arguing from Ignorance. Because we do not know how this universe came into being, we then have recourse to G-d. Personally, I do not know any argument from Design that is based upon arguing from ignorance. Arguments from Design are based upon the inconceivability of such lawful cooperating patterns co-existing for millennia simply occurring from chance. The argument from chance as an argument for the origin of the universe is the best example of an argument from ignorance. If we do not know a cause, we can attribute the cause to chance. Chance becomes the conceptual waste basket for all inexplicable phenomena.

\section{Goldstein and Spinoza}

Because, for Krochmal, G-d is infinite, it is important to take note of Rebecca Goldstein's argument that human beings can know infinity without requiring recourse to G-d. Her argument, number 29 on her list, is that "Recursive rules allow a finite system ... to reason about an infinity of objects." 15 This is an assertion, not an argument. How can recursive rules allow the finite to reason about the infinite? This is what needs to be proven, not asserted. Her reasoning basically is that we can always add another number to whatever number we have. This is a rule for generating a potential infinite; this is not the same as comprehending an actual infinite. She also equates reasoning about with knowledge of. She states that "We have knowledge of the infinite ..." and later conflates this

\footnotetext{
${ }^{15}$ Goldstein 2010: 386.
} 
with the ability to add a number to whatever number we consider to be the greatest number to knowledge of the infinite. That we can do something which entails the capacity to increase the greatest finite indefinitely is not the same as possessing knowledge of the infinite. Being able to follow a rule is not the same as comprehending an infinite sum. She concludes that "Recursive rules allow a finite system to reason about an infinity of objects." She states that this ability refutes her third premise: "We could not have derived this knowledge of the infinite from the finite." The capacity for reasoning and calculation is not equivalent to knowledge. She has not explained how the finite can know the infinite. She has only shown that the finite can reason about the indefinitely finite.

This fallacious argument of hers is important to notice because the very problem of how can the finite know the infinite is the heart of Spinoza's argument for the existence of G-d. For Spinoza, only the infinite can know the infinite. Hence, if we know the infinite, it must be that G-d has planted the idea of infinity within us.

Earlier we took note of the fact that Spinoza rejected the argument from design because he reasoned that it would detract from G-d's perfection to posit an end outside of itself. On the other hand, Spinoza does think he has given an adequate argument for the existence of G-d with his argument that it explains how the finite can know the infinite. This argument is called the causal ontological argument.

Spinoza also utilizes the pure ontological argument. At the beginning of his Ethics, he argues that G-d's essence is his existence. One wonders whether Spinoza was inspired by the self-definition of G-d, "I am who am", with which G-d answers Moses when he inquires what is G-d. G-d is saying, as Spinoza says, that His essence is to exist, or more precisely, to have to exist. G-d is defining himself as eternal existence. He cannot not exist. "I am who am", translates into my essence (what I am) is identical to my existence (that I am). Ironically, while still to this day excommunicated from Judaism, Spinoza's famed definition of G-d is identical to and perhaps drawn from this Biblical source. This formulation is closer to Anselm's second argument (Proslogium III) and Goldstein's rendition of the ontological argument is the weaker first version (Proslogium II). Goldstein thinks this argument is absurd because it would imply for her, that unicorns would have to exist. ${ }^{16}$ But it does not hold for unicorns because unicorns do not have to exist. For Spinoza (and the Anselm of Proslogium III), G-d cannot not exist. His existence is necessary. This is not the case with unicorns.

Kant's refutation of the ontological argument (also of Proslogium II) is that even though it is better that I have 100 Thalers in my pocket than an imaginary 100 Thalers, this does not mean that I must have 100 Thalers in my pocket. There is no necessity that Kant have 100 Thalers in his pocket any more than it is necessary that a unicorn exist. Kant's "refutation" that existence is not a predicate is not true in the case of G-d. Existence is G-d's essence, both for the Hebrew Bible and Spinoza.

Because G-d's existence is necessary, Spinoza thinks that the argument from Design cannot be made. Earlier we have shown that we can argue from design because there is no reason to consider that G-d exists for the sake of the design. As we have seen above, there is also evidence that Spinoza himself, despite his argument against the argument for design, also presents arguments that can be employed on behalf of the argument from

${ }^{16}$ Goldstein 2010: 350. 
design in his $32^{\text {nd }}$ letter to Oldenberg (though he does not so employ them to this effect). There is no incompatibility between G-d's necessary existence and the argument from design.

\section{The argument from care}

The argument from care is an aspect of the Argument from Design. Krochmal thinks highly of this argument, though he does not label it as such. The point of the argument is that a designer would care for the design that He has created. The origin of this argument is in rabbinic literature. The story is told that when someone sees a burning palace, he inquires if the palace has an owner. The point behind this, from the point of view of the present author, is that an owner would not let his castle burn. ${ }^{17}$ If there is a G-d, He has an ethical obligation to care for the world. The design - for example, a palace - implies a complex and elegant construction. The designer would not create such a construction without caring for it. That it is in flames is an indicator that if there is a designer, that that designer is obliged to care for that which He has designed. Although this argument on its own cannot stand as an argument for the existence of a Deity — indeed it presumes it - it stands as an argument for G-d as a continuous caring G-d. It is man crying out, If You have created this world, You have an obligation to care for it! It is an ethical argument for G-d as one who should care for Her/His designed.

This is an argument against the $18^{\text {th }}$ Century theory of Deism that G-d simply started things off and then retreated from the scene. For Krochmal, G-d would not abandon His creation. In her 36 arguments for the existence of G-d (which Goldstein collects in order to "refute" them one by one), Goldstein does not include this side of the Argument from Design, the argument from caring for one's creation.

The Argument from Design explains to some extent the incredibly intricate, inordinately complex, harmonic existence of the universe. Thus, there is a designer. The further aspect of the argument from design is the argument from care. Would a designer simply neglect this magnificent edifice without caring for it? Would he leave it to decay, deteriorate and ultimately self-destruct? Of course, this is possible. But, like the Argument from Design versus chance and natural selection, it seems that the opposite is more plausible. The Argument from Care is not a proof. It enables one to move from a metaphysical argument for the existence of G-d to a religious one. It is another illustration of Abraham's negotiations with G-d over the fate of Sodom and Gomorrah. While Abraham lost that battle, he managed to change the ethical consciousness of G-d. Man can implore G-d to take better care of the world. This is the meaning of man's co-creating the world with G-d.

17 Genesis 39:1. Rabbah Sacks, in contrast, argues that the point of the story is that it is man's duty to extinguish the flames. Both explanations are correct. 


\section{BIBLIOGRAPHY}

Amir, Y. (2003), The Perplexity of Our Time: Rabbi Nachman Krochmal and Modern Jewish Existence, Modern Judaism 23, no. 3: 264-301.

Banbaji, A. (2012), Two Paradigms of Aesthetics in Haskalah Literary Criticism: From Satanov to Lebensohn, Hebrew Studies 53: 143-177 [http://www.jstor.org/stable/23344445].

Ginzberg, L., Stern, D. (2003), Legends of the Jews, Volumes 1-2 (2), Dulles, US: Jewish Publication Society. Web.

Goldstein, R. (2010), 36 Arguments for the Existence of God: A Work of Fiction, New York: Random House, Inc.

Green, A., Stump, E. (2015), Hidden Divinity and Religious Belief: New Perspectives, Cambridge: Cambridge University Press.

Greenberg, G. (2011), Emunot: Jewish Philosophy and Kabbalah: Modern Jewish Thinkers: From Mendelssohn to Rosenzweig, Brighton, MA, US: Academic Studies Press. Web.

Harris, J. (1993), Nachman Krochmal: Guiding the Perplexed of the Modern Age, (Modern Jewish Masters), New York: NYU Press.

Kant, I. (2007), Critique of Judgment, trans. J.C. Meredith, ed. N. Walker, New York: Oxford University Press.

Kant, I. (1998), Religion Within the Boundaries of Mere Reason, trans. A. Wood, G. Di Giovanni, Cambridge, NY: Cambridge University Press.

Katz, S.T. (2007), Wrestling with God: Jewish Theological Responses during and after the Holocaust, Cary, GB: Oxford University Press, USA.

Sacks, E. (2016), Law, Ethics, and the Needs of History: Mendelssohn, Krochmal, and Moral Philosophy, Journal of Religious Ethics 44: 352-377.

Schumacher-Brunhes, M. (2012), Enlightenment Jewish Style: The Haskalah Movement in Europe, Mainz: Leibniz Institute of European History URL: http://ieg-ego.eu/en/threads/european-networks/jewish-networks/marie-schumacher-brunhes-enlightenment-jewish-style-the-haskalahmovement-in-europe.

Silber, J. (2012), Kant's Ethics: The Good, Freedom, and the Will, Boston: De Gruyter. [http://library. soka.edu:80/record=b1583483 S0]

Spinoza, B. de (1891), The Chief Works of Benedict de Spinoza, trans. R.H.M. Elwes, London: George Bell \& Sons. Web.

Spinoza, B. (1951), Ethics: Ethica Ordine Geometrico Demonstrata, trans. R.H.M. Elwes, Auckland, NZ: The Floating Press. Web.

Spinoza, B. (1985), Appendix of The Collected Works of Spinoza, Volume I, trans. E. Curley, Princeton: Princeton University Press.

Wolf, A. (1905), Dr. J.L. Landau's 'Nachman Krochmal', The Jewish Quarterly Review 17, no. 3: 592594. doi:10.2307/1450989 